\title{
Long-Term Potentiation in the Rat Medial Vestibular Nuclei Depends on Locally Synthesized $17 \beta$-Estradiol
}

\author{
Silvarosa Grassi, Adele Frondaroli, Cristina Dieni, Mariangela Scarduzio, and Vito E. Pettorossi \\ Department of Internal Medicine, Section of Human Physiology, University of Perugia, I-06126 Perugia, Italy
}

In male rat brainstem slices, we investigated the involvement of locally synthesized $17 \beta$-estradiol $\left(\mathrm{E}_{2}\right)$ in the induction in the medial vestibular nucleus (MVN) of long-term potentiation (LTP) by high-frequency stimulation (HFS) of the primary vestibular afferents. We demonstrated that the blockade of aromatase by letrozole or of $\mathrm{E}_{2}$ receptors (ER $\alpha$ and $\mathrm{ER} \beta$ ) by ICI 182,780 prevented the HFS-induced LTP of the N1 wave of the evoked field potential (FP) without affecting baseline responses. Only prolonged afferent activation could induce low LTP. In contrast, HFS applied under a combined blockade of $\mathrm{GABA}_{\mathrm{A}}$ receptors and aromatase or ERs was still able to induce LTP, but it was significantly lower and slower. These findings demonstrate that $\mathrm{E}_{2}$ does not have a tonic influence on the activity of the MVN neurons and provide the first evidence of the crucial role played by local synthesis of $\mathrm{E}_{2}$ in inducing LTP. We suggest that the synthesis of $\mathrm{E}_{2}$ occurs after aromatase activation during HFS and facilitates the development of vestibular synaptic plasticity by influencing glutamate and GABA transmission.

\section{Introduction}

Through genomic and nongenomic mechanisms, $17 \beta$-estradiol $\left(\mathrm{E}_{2}\right)$ modulates neuronal excitability and synaptic transmission (McEwen, 2002). The fast nongenomic effects are mediated by specific membrane receptors $(\mathrm{ER} \alpha$ and $\mathrm{ER} \beta)$ and G-proteincoupled receptors (GPR-30 and ER-X) (Toran-Allerand et al., 2002; Qiu et al., 2003; Pedram et al., 2006; Morisette et al., 2008; Raz et al., 2008) that regulate ligand-gated ion channels and neurotransmitter transporters (Wong et al., 1996; Kelly et al., 2002; Levin, 2002; Carrer et al., 2003; Dominguez et al., 2007). Through these mechanisms, $\mathrm{E}_{2}$ rapidly increases signal transmission by facilitating non-NMDA and NMDA receptors (NMDARs) (Wong and Moss, 1992; Gu and Moss, 1996; Foy et al., 1999), and inhibiting GABA release (Murphy et al., 1998; Rudick and Wooley, 2001). Moreover, $\mathrm{E}_{2}$ facilitates longterm potentiation (LTP) in the hippocampus through NMDARs (Wong and Moss, 1992; Foy et al., 1999; Foy, 2001) and influences cerebellar LTP (Andreescu et al., 2007). Recently, we also showed in vitro that the administration of $\mathrm{E}_{2}$ causes long-term enhancement of glutamatergic synaptic responses in the medial vestibular nucleus $(\mathrm{MVN})$, whose induction depends on NMDARs. Such $\mathrm{E}_{2}$ effect occludes the NMDAR-dependent LTP induced by the high-frequency stimulation (HFS) of vestibular afferents (Capocchi et al., 1992; Grassi and Pettorossi, 2001; Grassi et al., 2009, Scarduzio et al., 2009).

These effects of $E_{2}$ can be induced not only by gonadal $E_{2}$ but also by neural $\mathrm{E}_{2}$, which is synthesized in the brain through

Received April 7, 2009; revised July 28, 2009; accepted July 29, 2009.

We received financial support from MIUR-COFIN 2007 and the Fondazione Cassa di Risparmio di Terni and would like to thank D. Bambagioni and E. Mezzasoma for their outstanding technical assistance and C. E. Bolton for English language advice.

Correspondence should be addressed to Silvarosa Grassi, Department of Internal Medicine, Section of Human Physiology, University of Perugia, Via del Giochetto, I-06100 Perugia, Italy. E-mail: sgrassi@unipg.it.

DOl:10.1523/JNEUROSCI.1697-09.2009

Copyright $\odot 2009$ Society for Neuroscience ～0270-6474/09/2910779-05\$15.00/0 an aromatase-dependent conversion of testosterone regulated by neuronal activity (Naftolin et al., 1975; Simpson et al., 1994; Baulieu, 1997; Kimoto et al., 2001; Hojo et al., 2004; Balthazart and Ball, 2006; Mukai et al., 2006; Hojo et al., 2008). Since vestibular neurons express aromatase (Horvath and Wikler, 1999), it seems likely that neural $E_{2}$ plays a specific role in vestibular synaptic transmission and plasticity.

This study was designed to investigate, in the rat MVN, the possible involvement of neural $\mathrm{E}_{2}$ in modulating baseline synaptic responses and HFS-dependent LTP (Capocchi et al., 1992; Grassi and Pettorossi, 2001) through its possible interaction with glutamatergic and GABAergic transmission. In baseline conditions and after HFS, we analyzed the effects of aromatase or ER blockade, which prevent the production and action of neural $\mathrm{E}_{2}$. These analyses were conducted in brainstem slices prepared from male rats to avoid the influence of cyclic fluctuations of gonadal $\mathrm{E}_{2}$.

\section{Materials and Methods}

Slice preparation. Transverse brainstem slices (350 $\mu \mathrm{m}$ thick) containing the MVN were prepared from P18-22 male Wistar rats (Charles River) as previously described (Capocchi et al., 1992; Grassi et al., 1995). Slices were allowed to equilibrate for $1 \mathrm{~h}$ in warmed $\left(30 \pm 1^{\circ} \mathrm{C}\right)$ artificial CSF (aCSF) containing (in $\mathrm{mM}$ ): $124 \mathrm{NaCl}, 3 \mathrm{KCl}, 1.25 \mathrm{KH}_{2} \mathrm{PO}_{4}, 26 \mathrm{NaHCO}_{3}$, $3.4 \mathrm{CaCl}_{2}, 2.5 \mathrm{MgSO}_{4}, 10 \mathrm{D}$-glucose and $2 \mathrm{~L}$-ascorbate, saturated with $95 \% \mathrm{O}_{2}$ and $5 \% \mathrm{CO}_{2}(\mathrm{pH} \sim 7.4)$. The slices were then transferred to an interface-type recording chamber and perfused at a rate of $2 \mathrm{ml} / \mathrm{min}$.

Extracellular recordings. The field potential (FP) elicited by vestibular afferent stimulation was recorded in the ventral part of the MVN $(\mathrm{Mv})$ with micropipettes filled with $2 \mathrm{M} \mathrm{NaCl}$ (Fig. $1 A$ ). Vestibular afferents were stimulated by placing a bipolar Pt/Ir electrode at the point where they enter the MVN, which is in a narrow zone at the medial border of the lateral or descending vestibular nucleus (Fig. 1A). Stimulation in this area makes it possible to evoke a direct response to vestibular afferent activation and induce LTP (Capocchi et al., 1992; Grassi and Pettorossi, 2001). Electrical pulses with a duration of $0.07 \mathrm{~ms}$ and an intensity of $40-100 \mu \mathrm{A}$ were used at a frequency of $0.06 \mathrm{~Hz}$ as a test stimulation, and 
at $100 \mathrm{~Hz}$ (HFS, four bursts applied with alternated polarity for $2 \mathrm{~s}$, with an interval of $5 \mathrm{~s}$ ) as conditioning stimulation.

The recorded responses were amplified, filtered $(0-10 \mathrm{kHz})$, and stored in a computer (Pentium PC) equipped with a data acquisition card (AT-MIO-16E-2, National Instruments). The evoked FP consisted of a presynaptic component $(\mathrm{P})$, which follows the stimulus artifact, and a large negative wave (N1), which represents the monosynaptic activation of the secondary vestibular neurons (Fig. $1 B$ ). The relatively low electrode resistance (2-4 M $\Omega$ ) minimized the possibility of recording unitary activity that could alter the FP shape. If single spikes were present, the response was discarded. The amplitude of the N1 wave was measured as the difference between the wave peak negative voltage and the baseline (Fig. 1B). As reported previously (Grassi et al., 1996), the postsynaptic nature of the N1 wave and its dependence on the activation of AMPAR- and NMDARmediated glutamatergic transmission were verified (Fig. 1B)

Drugs. To block the neural production of $\mathrm{E}_{2}$, we used letrozole, a reversible nonsteroidal aromatase inhibitor (Bhatnagar et al. 2001; 100 $\mathrm{nm}$, generously provided by Novartis Pharma). In some experiments, we also used $17 \beta$ estradiol ( $\mathrm{E}_{2}, 1 \mathrm{~nm}$, Steraloids). In addition, we used the antagonists for the following receptors: $\mathrm{ER} \alpha$ and $\mathrm{ER} \beta$ (ICI 182,780, $100 \mathrm{~nm}$ ), NMDA (AP-5, $100 \mu \mathrm{M}$ ), AMPA (NBQX, 10 $\mu \mathrm{M}$ ), and $\mathrm{GABA}_{\mathrm{A}}$ (bicuculline, $30 \mu \mathrm{M}$ ), which were purchased from Tocris. The antagonist concentrations were chosen according to the efficacious dose ranges reported in the literature. Stock solutions of bicuculline, AP-5, and NBQX $(10 \mathrm{~mm})$ were dissolved in distilled water, while stock solutions of $\mathrm{E}_{2}(0.1 \mathrm{~mm})$, letrozole $(10 \mathrm{~mm})$, and ICI 182,780 (10 mM) were dissolved in dimethyl sulfoxide (DMSO). The drugs were diluted to working concentrations in oxygenated aCSF before use and perfused at a rate of $2 \mathrm{ml} /$ min. Drug administration was considered to have commenced when the drug reached its steady concentration in the recording chamber, whereas the duration of drug infusion varied according to the experimental protocol.

Analysis. The amplitude of the FP-N1 wave, recorded under stable conditions at the start of each experiment, was used as a baseline, and its modifications induced by drugs or HFS were expressed as a percentage of baseline. To compare these effects within a single experiment, we considered the mean \pm SD over 5 min intervals before the administration of drugs or HFS (control), at steady state after the start of drug perfusion or after HFS, and at 35-40 min after HFS to control possible long-term modifications. The changes induced by drugs or HFS were considered potentiation and depression only when they were significantly different from the control ( $p<0.05$, Student's paired $t$ test).

The frequency of potentiation, depression, or no effect after the application of HFS under different drugs was compared using the chi square $\left(\chi^{2}\right)$ test. Statistical significance was established at $p<0.05$. All the statistical analyses were performed with SigmaStat (SSI).

\section{Results}

Neural $E_{2}$ is not involved in modulation of the baseline evoked FP in the MVN

The amplitude of the evoked FP-N1 wave was analyzed in the presence of the aromatase inhibitor letrozole (32 slices, 9 animals) and the selective ER antagonist ICI 182,780 (25 slices, 7 animals). The baseline $\mathrm{N} 1$ wave was not modified by letrozole or ICI (Fig. $1 C, D$ ). Moreover, exogenous $\mathrm{E}_{2}$, which has been reported to cause long-term enhancement of N1 wave (Grassi et al., 2009; Scarduzio et al., 2009), was still able to induce N1 potentiation $(125.6 \pm 4.7 \%, n=6, p<0.05)$ in the presence of letrozole (Fig. $1 C$ ), but not in the presence of ICI (4 slices, Fig. $1 D$ ).

\section{Neural $E_{2}$ is involved in the induction of HFS-LTP in the MVN}

The influence of neural $\mathrm{E}_{2}$ on LTP was analyzed by evaluating the effect of HFS applied $30 \mathrm{~min}$ after the beginning of letrozole (10 slices) and ICI (11 slices) administration. As a control, we used $10^{-4} \%$ DMSO, i.e., the solvent used for the two drugs, (7 slices, 2 animals). With DMSO the baseline $\mathrm{N} 1$ wave was not modified, and LTP induced by HFS was similar (frequency: 5 of 7 slices; amplitude: $131.3 \pm 4.2 \%$; rise time: $5.3 \pm 1.5 \mathrm{~min}$ ) to that observed in our previous studies with normal aCSF (Capocchi et al., 1992; Grassi and Pettorossi, 2001) (Fig. 2A,B,D).

Conversely, with letrozole, HFS was never able to induce LTP. Indeed, no effect was observed in 8 of 10 slices (Fig. $2 A, D, N E$ ); in the remaining 2 slices HFS induced a persistent reduction of the N1 wave to $84.1 \pm 2 \%(p<0.05)$ (Fig. $2 A, D$, LTD). The distribution of LTP and LTD after HFS with letrozole differed signifi- 

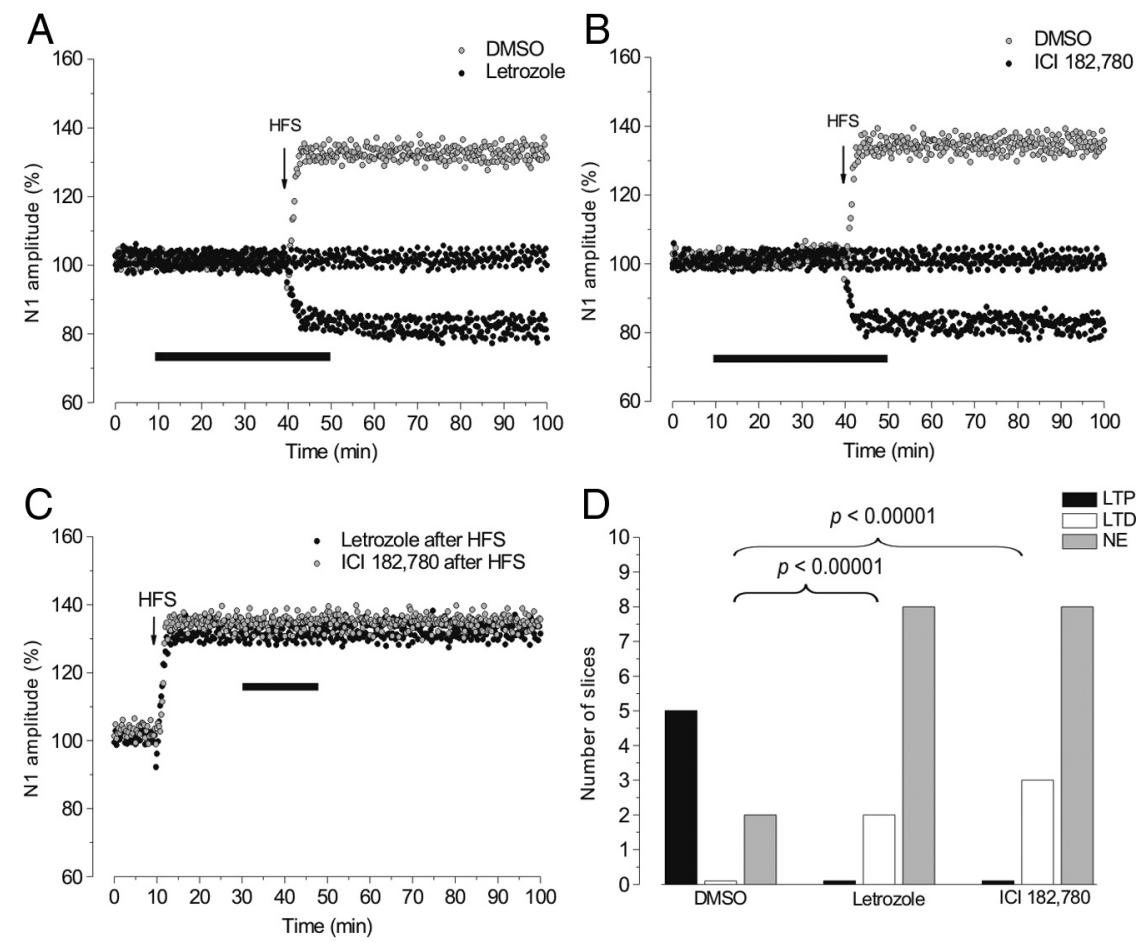

Figure 2. The effects of letrozole and ICI on HFS-LTP. $A, B$, Time courses of the effects of HFS applied with DMSO (gray circles) or letrozole (black circles) ( $\boldsymbol{A}$ ) and with DMSO (gray circles) or ICI (black circles) (B). C, The effects of letrozole (black circles) or ICI (gray circles) administered after inducing $\mathrm{N} 1$ potentiation by HFS. In this figure and the ones that follow, the arrows indicate HFS delivery time. $\boldsymbol{D}$, The frequency of LTP (black columns), LTD (white columns), and no effect(NE, gray columns) induced by HFS with DMSO, letrozole, or ICI ( $p<0.00001, \chi^{2}$ test).

cantly compared with those observed with DMSO $\left(\chi^{2}=23\right.$, df $\left.=2, p<0.00001\right)$ (Fig. $2 D$ ). Similarly, with ICI HFS was unable to induce LTP, showing no effect in 8 of 11 slices and $3 \operatorname{LTD}(83.5 \pm 3 \%, n=3, p<$ 0.05 ) (Fig. $2 B, D$ ). The frequency of the effects was similar to what was observed with letrozole ( $\chi^{2}$ test, $\left.p>0.05\right)$, but differed significantly with respect to DMSO $\left(\chi^{2}=23\right.$, $\mathrm{df}=2, p<0.00001$ ) (Fig. 2D). On the contrary, letrozole (3 slices) or ICI (3 slices) did not modify LTP $(132.2 \pm 4.2 \%, p<0.05)$, when it was already established (Fig. 2C).

We also increased duration ( 8 trains in 4 slices and 16 trains in 4 slices, at $100 \mathrm{~Hz}$ ) and frequency ( 4 trains in 4 slices, at $200 \mathrm{~Hz}$ ) of stimulation to investigate whether different HFS patterns could induce LTP in the presence of letrozole. Low-amplitude LTP $(116 \pm 4.7 \%, p<0.05)$ was only observed after 16 trains at $100 \mathrm{~Hz}$ ( 3 of 4 slices), while all the other stimulations provoked no effect or depression (data not shown).

Influence of the time interval between the administration of aromatase inhibitor and HFS

HFS was also delivered after $5 \mathrm{~min}$ (9 slices) and $2.5 \mathrm{~min}$ ( 7 slices) of letrozole or ICI application. At the time interval of 5
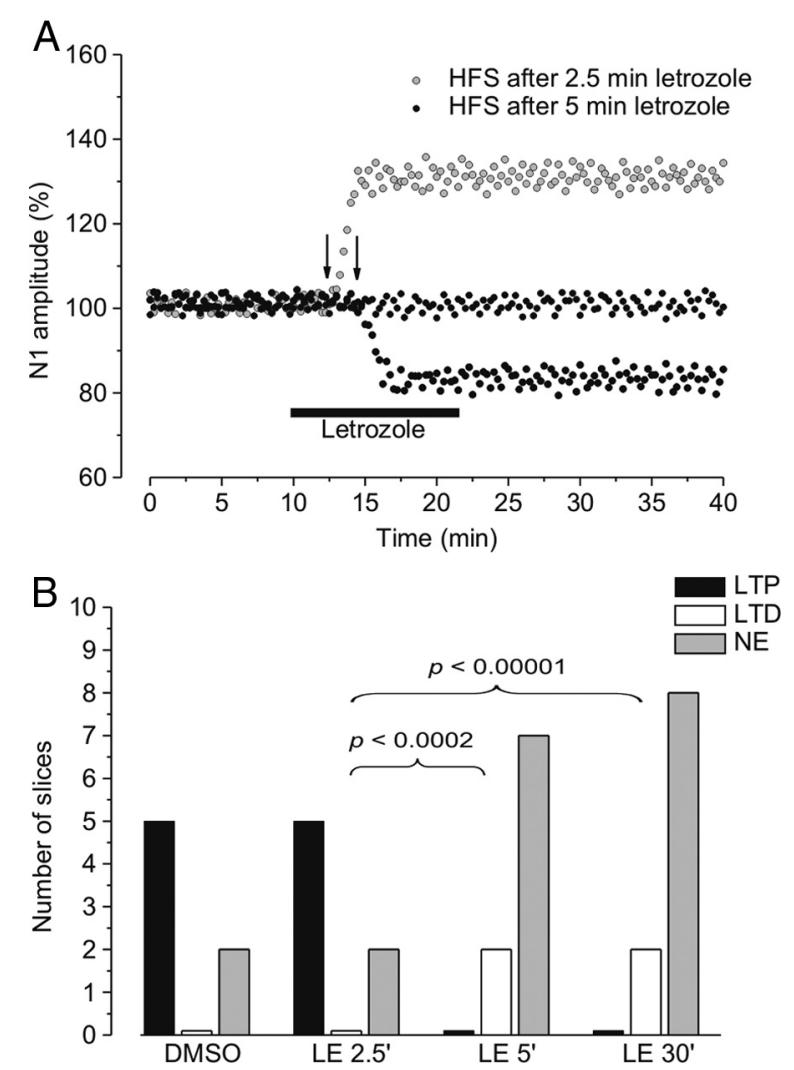

Figure 3. The effect of HFS at the different aromatase blockade times. $A$, Time courses of the effects of HFS delivered $2.5 \mathrm{~min}$ (gray circles) or $5 \mathrm{~min}$ (black circles) after letrozole. $\boldsymbol{B}$, The frequency of LTP (black columns), LTD (white columns), and no effect (NE, gray columns) induced by HFS in the presence of DMSO and at 2.5,5, and $30 \mathrm{~min}$ after letrozole was administered $\left(p<0.0002\right.$ and $0.00001, \chi^{2}$ test $)$. min there was no change in the frequency of the HFS effects, compared with a longer interval $(30 \mathrm{~min})\left(\chi^{2}\right.$ test, $\left.p>0.05\right)$ (Fig. $3 B)$, but at a shorter interval (2.5 min) LTP was inducible (Fig. $3 A$ ) and its frequency was similar to that observed with DMSO (letrozole: 5 of 7 slices, Fig. $3 B$; ICI: 3 of 4 slices, data not shown).

In the cases in which 5 min of letrozole administration prevented induction of HFS-LTP, a second HFS applied at the letrozole washout (30-60 min after the end of drug infusion) was still unable to induce LTP (data not shown), suggesting a long-lasting inhibition of aromatase.

Effect of HFS under a combined blockade of $\mathrm{GABA}_{\mathrm{A}}$ receptors and aromatase or $\mathrm{GABA}_{\mathrm{A}}$ receptors and ERs

HFS was applied under a combined blockade of $\mathrm{GABA}_{\mathrm{A}} \mathrm{Rs}$ and letrozole (11 slices, 4 animals) or $\mathrm{GABA}_{\mathrm{A}}$ Rs and ERs ( 8 slices, 3 animals) and the effects were compared with those induced by HFS in the presence of bicuculline alone ( 8 slices, 3 animals). In all the slices, bicuculline significantly increased the amplitude of the N1 wave to $113.4 \pm 3.8 \%(n=27, p<0.05)$, while no modification was observed with the subsequent administration of letrozole $(113.5 \pm 3.7 \%, n=11, p>0.05)$ and ICI $(112.7 \pm$ $3.5 \%, n=8, p>0.05$; Fig. $4 A, B)$. With bicuculline alone, LTP induced by HFS occurred with the same frequency ( 6 of 8 slices) to what we observed with DMSO ( $\chi^{2}$ test, $\left.p>0.05\right)$. The N1 wave increased to $132.9 \pm 3.4 \%$ of the prebicuculline value, an amplitude similar to that of the control LTP. However, by considering the enhancement of N1 amplitude caused by bicuculline, the magnitude of LTP was actually lower (119\%, Student's $t$ test, $p<$ 0.05). Moreover, the rise time of LTP was unchanged (5.72 \pm 1.9 min) (Fig. $4 A, B, D$ ).

Letrozole or ICI, administered under bicuculline, did not modify the frequency of $\mathrm{N} 1$ potentiation ( 8 of 11 slices and 6 of 8 slices, respectively, $\chi^{2}$ test, $p>0.05$; Fig. $4 C$ ). Nevertheless, these 
potentiations were lower with respect to LTP by HFS in the presence of bicuculline alone (letrozole $111.7 \pm 3.4 \%$ and ICI $110.9 \pm 4.1 \%, p<0.05)$ and had a longer rise time (letrozole $16.8 \pm 4.5 \mathrm{~min}$ and ICI $19.4 \pm 6.6 \mathrm{~min}, p<0.05$ ) (Fig. $4 A, B, D, E)$.

\section{Discussion}

This study shows that blocking aromatase, the enzyme that synthesizes $E_{2}$, did not affect the baseline glutamatergic synaptic responses of the MVN neurons, but it did prevent LTP induced by HFS of the primary vestibular afferent. Rather than inducing LTP, HFS had no effect, or it caused depression of the FP-N1 wave, and a low LTP could only be observed after very long HFS. In contrast, once potentiation settled, aromatase inactivation did not influence it. LTP induction was also prevented by the ER antagonist (ICI 182, 780 ), suggesting that $E_{2}$ influences vestibular LTP by interacting with ER $\alpha$ or ER $\beta$. Therefore, we can conclude that $\mathrm{E}_{2}$, synthesized locally by aromatase, does not play a role during normal neuronal activity, but is crucial for LTP induction. The mechanisms by which $\mathrm{E}_{2}$ influences LTP seem to point to both glutamate and GABA transmission. It has been reported that $\mathrm{E}_{2}$ facilitates LTP by interacting with NMDARs (Wong and Moss, 1992; Foy et al., 1999; Foy, 2001), and it inhibits GABA release (Murphy et al., 1998; Rudick and Wooley, 2001). One of the reasons we suggest that $\mathrm{E}_{2}$ influences vestibular LTP by interacting with NMDARs is based on the fact that it requires NMDAR activation (Grassi and Pettorossi, 2001), and exogenous $\mathrm{E}_{2}$ enhances NMDAR-dependent responses (Grassi et al., 2009; Scarduzio et al., 2009). Indeed, in the absence of GABA, LTP by HFS was consistently lower and delayed without $\mathrm{E}_{2}$. Conversely, the role of GABA can be inferred by considering the frequency of LTP occurrence. In the presence of GABAergic activity, LTP was fully prevented by blocking $\mathrm{E}_{2}$ synthesis, whereas LTP was inducible when $\mathrm{GABA}_{\mathrm{A}}$ Rs and aromatase were blocked. This suggests that LTP induction requires the reduction of GABAergic input on the MVN neurons. However, the interaction of $E_{2}$ with GABA is problematic, namely by considering the amplitude of LTP induced in the presence of bicuculline. In fact, since bicuculline enhanced baseline N1 wave we should not expect LTP lower than that observed in control conditions. An explanation could be that LTP may be maintained in part through the reduction of GABA release or sensitivity and in part through an increase in glutamatergic function. Therefore, bicuculline might occlude the suppression of GABAergic function. Alternatively, if the amplitude of LTP is only dependent on glutamatergic potentiation, the low amplitude under bicuculline could be explained by the presence of a limiting factor, which avoids excessive potential enhancements (Grassi and Pettorossi, 2001). This seems to be likely, since we never observed greater LTP by using higher frequency of stimulation $(200 \mathrm{~Hz})$.

In this view, we suggest that the effect of $\mathrm{E}_{2}$ in reducing the GABAergic function is relevant for LTP induction. In fact, the lack of a shunting IPSP may contribute to a greater depolarization during HFS, which facilitates induction of NMDARdependent LTP.

On the whole, we suggest that vestibular LTP requires the combination of two events: decreased GABAergic inhibition and an increase in glutamatergic excitatory effects. Moreover, these two mechanisms elicited by neural $\mathrm{E}_{2}$ appear to be necessary for LTP, since low LTP was induced under letrozole only after very long afferent stimulation.

The effect of aromatase blockade was almost immediate, since HFS delivered after 5 min of letrozole administration did not induce LTP, a finding that excludes a relevant storage of $\mathrm{E}_{2}$. LTP was only inducible at an interval of $2.5 \mathrm{~min}$ between the administration of letrozole and HFS application, and this is consistent with the time required to reach the full drug effect in our experimental condition. In addition, we suggest that aromatase may be activated during HFS, since we did not observe any effect of its blockade on the baseline neuronal activity, which is instead influenced by exogenous $\mathrm{E}_{2}$, as shown in this study as well as our previous works (Grassi et al., 2009; Scarduzio et al., 2009). This may indicate that, by activating aromatase, HFS produces a significant amount of $E_{2}$. The regulation of aromatase activity by synaptic stimulation has been reported in other studies (Hojo et al., 2004, 2008; Balthazart and Ball, 2006) showing enzyme activation during synaptic activation after an increase in presynaptic or postsynaptic $\mathrm{Ca}^{2+}$ levels. However, we cannot exclude the tonic activity of aromatase, since neural $\mathrm{E}_{2}$ may become operative and lead to a significant modification of glutamatergic and GABAergic responses only during the increase of afferent inputs. 
In conclusion, this study confirms the influence of $\mathrm{E}_{2}$ on vestibular neuronal activity, as previously reported for exogenous $\mathrm{E}_{2}$ (Grassi et al., 2009; Scarduzio et al., 2009). For the first time, however, it demonstrates that neural $\mathrm{E}_{2}$ plays a specific role in the synaptic plasticity of the CNS, without influencing baseline neuronal activity.

The LTP of vestibular glutamatergic synapses represents an important mechanism that may be useful in inducing and stabilizing various plastic phenomena in the vestibular circuitry, such as those that occur during visuo-vestibular recalibration and vestibular compensation. In this context, neural $\mathrm{E}_{2}$ seems to be a very effective modulator that facilitates this process through a double mechanism: increased excitatory glutamatergic transmission and reduced inhibitory GABAergic transmission.

\section{References}

Andreescu CE, Milojkovic BA, Haasdijk ED, Kramer P, De Jong FH, Krust A, De Zeeuw CI, De Jeu MT (2007) Estradiol improves cerebellar memory formation by activating estrogen receptor $\beta$. J Neurosci 27:10832-10839.

Balthazart J, Ball GF (2006) Is brain estradiol a hormone or a neurotransmitter? Trends Neurosci 29:241-249.

Baulieu EE (1997) Neurosteroids: of the nervous system, by the nervous system, for the nervous system. Rec Prog Horm Res 52:1-32.

Bhatnagar AS, Brodie AM, Long BJ, Evans DB, Miller WR (2001) Intracellular aromatase and its relevance to the pharmacological efficacy of aromatase inhibitors. J Steroid Biochem Mol Biol 76:199-202.

Capocchi G, Della Torre G, Grassi S, Pettorossi VE, Zampolini M (1992) NMDA-mediated long term modulation of electrically evoked field potentials in the rat medial vestibular nuclei. Exp Brain Res 90:546-550.

Carrer HF, Araque A, Buño W (2003) Estradiol regulates the slow $\mathrm{Ca}^{2+}$ activated $\mathrm{K}^{+}$current in hippocampal pyramidal neurons. J Neurosci 23:6338-6344

Dominguez R, Liu R, Baudry M (2007) $17-\beta$-Estradiol-mediated activation of extracellular-signal regulated kinase, phosphatidylinositol 3-kinase/ protein kinase B-Akt and $\mathrm{N}$-methyl-D-aspartate receptor phosphorylation in cortical synaptoneurosomes. J Neurochem 101:232-240.

Foy MR (2001) 17 $\beta$-Estradiol: effects on CA1 hippocampal synaptic plasticity. Neurobiol Learn Mem 76:239-252.

Foy MR, Xu J, Xie X, Brinton RD, Thompson RF, Berger TW (1999) $17 \beta$ Estradiol enhances NMDA receptor-mediated EPSPs and long-term potentiation. J Neurophysiol 81:925-929.

Grassi S, Pettorossi VE (2001) Synaptic plasticity in the medial vestibular nuclei: role of glutamate receptors and retrograde messengers in rat brainstem slices. Prog Neurobiol 64:527-553.

Grassi S, Della Torre G, Capocchi G, Zampolini M, Pettorossi VE (1995) The role of Gaba in NMDA-dependent long term depression (LTD) of rat medial vestibular nuclei. Brain Res 699:183-191.

Grassi S, Pettorossi VE, Zampolini M (1996) Low frequency stimulation cancels the high frequency-induced long lasting effects in the rat medial vestibular nuclei. J Neurosci 16:3373-3380.

Grassi S, Frondaroli A, Dieni C, Scarduzio M (2009) Effects of $17 \beta$-estradiol on synaptic plasticity in the rat medial vestibular nuclei. Acta Otolaryngol 129:390-394

Gu Q, Moss RL (1996) 17 $\beta$-Estradiol potentiates kainate-induced currents via activation of the cAMP cascade. J Neurosci 16:3620-3629.

Hojo Y, Hattori TA, Enami T, Furukawa A, Suzuki K, Ishii HT, Mukai H, Morrison JH, Janssen WG, Kominami S, Harada N, Kimoto T, Kawato S (2004) Adult male rat hippocampus synthesizes estradiol from preg- nenolone by cytochromes P450 17alpha and P450 aromatase localized in neurons. Proc Natl Acad Sci U S A 101:865-870.

Hojo Y, Murakami G, Mukai H, Higo S, Hatanaka Y, Ikeda MO, Ishii H, Kimoto T, Kawato S (2008) Estrogen synthesis in the brain. Role on synaptic plasticity and memory. Mol Cell Endocrinol 290:31-43.

Horvath TL, Wikler KC (1999) Aromatase in developing sensory system in the rat brain. J Neuroendocrinol 11:77-84.

Kelly MJ, Qiu J, Wagner EJ, Rønnekleiv OK (2002) Rapid effects of estrogen on $G$ protein-coupled receptor activation of potassium channels in the central nervous system (CNS). J Steroid Biochem Mol Biol 83:187-193.

Kimoto T, Tsurugizawa T, Ohta Y, Makino J, Tamura H, Hojo Y, Takata N, Kawato S (2001) Neurosteroid synthesis by citochrome p450-containing systems localized in the rat brain. Endocrinology 142:3578-3589.

Levin ER (2002) Cellular functions of plasma membrane estrogen receptors. Steroids 67:471-475.

McEwen BS (2002) Estrogen actions throughout the brain. Recent Prog Horm Res 57:357-384.

Morisette M, Le Saux M, D'Astous M, Jourdain S, Sweidi SA, Morin N, Estrada-Camarena E, Mendez P, Garcia-Segura LM, Di Paolo T (2008) Contribution of estrogen receptors alpha and beta to the effects of estradiol in the brain. J Steroid Biochem Mol Biol 108:327-338.

Mukai H, Takata N, Ishii HT, Tanabe N, Hojo J, Furukawa A, Kimoto T, Kawato S (2006) Hippocampal synthesis of estrogens and androgens which are paracrine modulators of synaptic plasticity: synaptocrinology. Neurosci 138:757-764.

Murphy DD, Cole NB, Greenberger V, Segal M (1998) Estradiol increases dendritic spine density by reducing GABA neurotransmission in hippocampal neurons. J Neurosci 18:2550-2559.

Naftolin F, Ryan KJ, Davies IJ, Petro Z, Kuhn M (1975) The formation and metabolism of estrogens in brain tissues. Adv Biosci 15:105-121.

Pedram A, Razandi M, Levi AR (2006) Nature of functional estrogen receptors at the plasma membrane. Mol Endocrinol 20:1996-2009.

Qiu J, Bosch MA, Tobias SC, Grandy DH, Scanlan TS, Ronnekleiv OK, Kelly MJ (2003) Rapid signalling of estrogen in hypothalamic neurons involves a novel G-protein-coupled estrogen receptor that activates protein kinase C. J Neurosci 23:9529-9540.

Raz L, Khan MM, Mahesh VB, Vadlamudi RK, Brann DW (2008) Rapid estrogen signalling in the brain. Neurosignals 16:140-153.

Rudick CN, Wooley CS (2001) Estrogen regulates functional inhibition of hippocampal CA1 pyramidal cells in the adult female rat. J Neurosci 21:6532-6543.

Scarduzio M, Dieni C, Grassi S (2009) Influence of $17 \beta$-estradiol on synaptic transmission and neuron excitability in the rat medial vestibular nuclei. Trab Inst Cajal 82:278-279.

Simpson ER, Mahendroo MS, Means GD, Kilgore MW, Hinshelwood MM, Graham-Lorence S, Amarneh B, Ito Y, Fisher CR, Michael MD (1994) Aromatase cytochrome P450, the enzyme responsible for estrogen biosynthesis. Endocr Rev 15:342-355.

Toran-Allerand CD, Guan X, MacLusky NJ, Hovath TL, Diano S, Singh M, Connolly ES Jr, Nethrapalli IS, Tinnikov AA (2002) ER-X: a novel, plasma membrane-associated, putative estrogen receptor that is regulated during development and after ischemic brain injury. J Neurosci 22:8391-8401.

Wong M, Moss RL (1992) Long-term and short-term electrophysiological effects of estrogen on the synaptic properties of hippocampal CA1 neurons. J Neurosci 12:3217-3225.

Wong M, Thompson TL, Moss RL (1996) Nongenomic actions of estrogen in the brain: physiological significance and cellular mechanisms. Cr Rev Neurosci 10:189-203. 